\title{
Note on the Regeneration of the Gill of Mytilus edulis.
}

By

D. Atkins, B.Sc.

With 8 Figures in the Text.

\section{INTRODUCTION.}

In connexion with work on reversal of the frontal cilia on the gill filaments of Mytilus edulis (1), it became desirable to know whether the gills were capable of regeneration after injury. With the exception of the peculiar method of growth or regeneration of the incubatory gills in Cyclas, briefly described by Poyarkoff (11), which, even if his preliminary observations are confirmed, would hardly appear to be true regeneration, ${ }^{*}$ the only reference that can be found on the subject of regeneration of the gills in Lamellibranchs is that in the paper by Bloomer (3) on malformed specimens of Anodonta cygnea, where the condition was apparently due to injury : he concluded " that the animal is able to repair even extensive damage to the mantle-lobes, but is not able to make good injuries to the gills" (3, p. 138).

As $M$. edulis is not infrequently found having the gills with very jagged ventral edges, and a few specimens even with the gills more or less entirely missing for a short length-in some instances almost certainly attributable to injury by boring whelk-tingles-it was thought that regeneration of gill filaments possibly might not occur in Mytilus. A single specimen experimented on in June, 1929, showed no signs, after 112 days, of regenerating the wedge-shaped pieces cut from the gills, beyond the formation of a food groove at the cut ends (see 1, p. 960). From further experiments, however, it is evident that regeneration of the gills of $M$. edulis may occur.

\section{EXPERIMENTS.}

Mussels with strong shells (ca. $7 \cdot 0-8 \cdot 0 \mathrm{~cm}$. long) were chosen for the experiments, so that the shells would not be likely to fracture easily on being forced open. The ease or difficulty with which the valves could be

* "La formation des sacs d'incubation doit gêner considérablement le développement normal du feuillet réfléchi de la lame branchiale interne. En revanche ce feuillet s'accroît d'une façon si singulière que je qualifierai ce cas de régénération de ce feuillet bien que sans doute l'animal n'en perde en réalité aucune portion " (11, p. exxxvi). 
forced apart was taken as an indication of the condition of the mussel ; those of which the valves could be easily forced apart were rejected.

The shell was first opened slightly with an oyster opener ; the pointed and thin side of a wooden wedge inserted; worked further in and slowly twisted, until the mussel was forced open to the greatest width of the wedge (about 1.0 to $1.5 \mathrm{~cm}$.). It was done gradually so as to strain the muscles as little as possible. In spite of care the shell fractured badly in some few instances, and the mussels had to be discarded.

The injuries were made near the posterior end of the gills, ${ }^{*}$ owing to the difficulty of reaching any other part. So far as could be seen, the gills of all the mussels used were normal.

The experimental mussels were placed separately in finger bowls, and the bowls sunk in one of the glass-fronted tanks in the general circulation in the Plymouth Laboratory, the tank used being in the shade. $\dagger$ An average of two to four litres of tow nettings a day were tipped into the tank.

Temperature readings of the water in the experimental tank were not taken, but the highest and lowest morning readings (taken at about 9.30 a.m.) for each month, of water temperatures of a similar tank, three tanks away and on the same side of the building, are as follows :

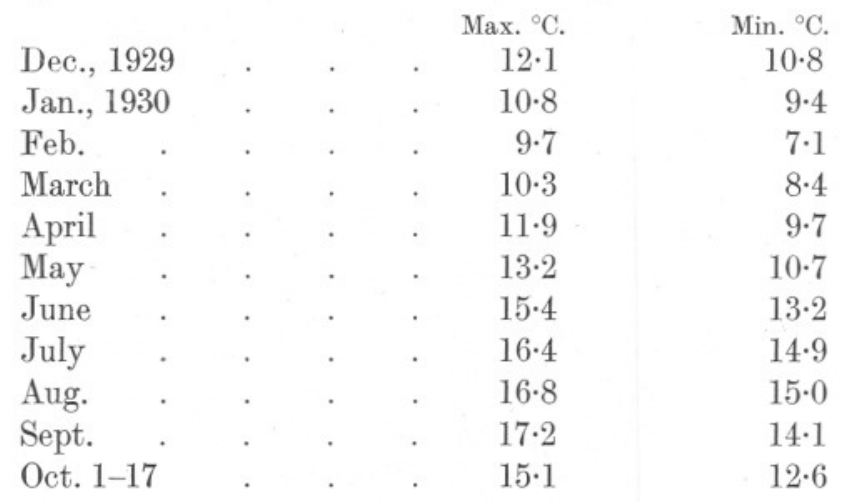

(These figures have been abstracted from the temperature readings taken daily by Mr. A. J. Smith.)

The experiments were started on November 29th and December 1st, 1929, and in February, two out of the ten experimental mussels were found to have died. Five individuals (A, C, D, F, K in Table I) were opened on July 30th, 1930 ; of the remaining three, one (E) was found gaping on September 15th, the two survivors (B and J) were opened on October 17th, 1930.

Notes on the experimental mussels are given in Table I.

* For convenience in description the two demibranchs on each side of the body are considered as two gills.

$\dagger$ Coulthard (6, p. 136) finds that " Mussels display maximum growth in approximately $50 \%$ sunlight, slightly less in darkness, and least in full sunlight." 
TABLE I.

\section{EXPERIMENTS ON REgenERATION IN THE GILL OF MYTILUS EDULIS.}

Date of opening in Mussel. 1930. A. July 30

Condition on date of opening.

A good deal of byssus formed; strongly attach ed. Mussel rather thin. Gills markedly pigmented.

9

B. Oct. 17

Rather poorly fished, but valves fairly stiff to force apart. Gills only slightly pigmented.
Nature of injury inflicted.

(a) Right inner gill.-Wedge-shaped piece cut out of ventral edge in such a way as to leave some filaments unattached except by ciliated dises.

(b) Left inner gill.-Two slanting cuts with scissors from ventral edge of gill in a dorsal and anterior direction, so as to isolate two pieces of gill except for attachment by ciliated dises.

(c) Left outer gill.-Operation as for left inner gill.

(a) Right outer gill.-Injured by pulling some of the filaments with forceps.

(b) Right inner gill.- Shallow piece cut out of ventral edge.

(c) Left inner gill.-A slanting cut with scissors from ventral edge in a dorsal and anterior direction, so as to isolate a piece of gill except for attachment by ciliated disc.

(d) Left outer gill.-Piece cut out of ventral edge.
Result.

(a) Regeneration both of food groove and filaments occurred (see Fig. 1).

(b) Pieces sloughed off : regeneration of food groove and of filaments followed (see Fig. 3).

(c) Pieces sloughed off : regeneration of food groove and of filaments followed (see Fig. 2).

(a) Regeneration of food groove occurred. Injury showed as two long inlets in gill, with some slight abnormality of filaments.

(b) Regeneration of food groove occurred, also some very slight regeneration, with apparent fusion, of filaments.

(c) Most of piece sloughed off. Little, if any, regeneration beyond formation of new food groove. At deep end of cut some irregular joining up of cut ends of filaments. Five or so short lengths of filaments separated dorsally from gill by a tiny space, but attached anteriorly and posteriorly.

(d) Regeneration of food groove occurred, also some slight regeneration, with apparent fusion, of filaments (see Fig. 5). 
Date of

opening in

Mussel. 1930.

C. July 30 of opening.

Much byssus formed; strongly attached. Fairly well fished. Gills very slightly pigmented, with practically no intensity of pigment along ventral edges.

D. July 30

Much byssus formed; strongly attached. Mussel in good condition.

E. Sept. 15

Valves gaping. Mussel thin.
Condition on date

TABLE I-(continued).

Nature of injury inflicted.

Result.

All four gills cut obliquely with No injury apparent when gills scalpel, the cuts not reaching the examined with microscope. Regeneraventral edge. In some cases the gill tion of epithelium occurred, and in cases

fusion of cut ends had also taken place. oyster opener (see p. 557).

\section{As for C.}

\section{As for C.}

As for C.

No injury apparent when gills examined with microscope; but a small piece missing from the ventral edge of left inner gill; one of the cuts may have been too near the edge of gill. Regeneration of epithelium had occurred, and in cases where filaments had been cut through, fusion of cut ends had also taken place.

Much byssus formed; All four gills cut obliquely with strongly attached. Mussel in good condition. Spawned as female, after being opened and put in finger bowl under circulation. scalpel, the cuts not reaching the
ventral edge. In all instances the gill ventral edge. In all instances the gill was supported by the blade of an oyster opener (see p. 557).

\section{Found dead.}

No injury apparent when gills examined with microscope. Regeneration of epithelium had occurred, and in cases where filaments had been cut through, fusion of cut ends had also taken place.

G. Feb. $2 \theta$

Found dead. 


\section{J. $\quad$ Oct. 17}

Poorly fished, valves easily forced apart. Gills very slightly pigmented.

\section{K. July 30}

Valves gaping somewhat; would not close when touched. Mussel in poor condition. Gills rather slightly pigmented, but with a darkly pigmented (brown) ventral edge. (a) Right inner gill.-A slanting cut with scissors from ventral edge in a dorsal and anterior direction, so as to isolate a piece of gill except for attachment by ciliated dises.

(b) Right outer gill.-Cut obliquely with scalpel in several places, cuts not reaching the ventral edge. Gill not supported (see p. 557).

(c) Left inner gill.-As for right outer gill $(b)$, but gill supported by blade of oyster opener (see p. 557).

(d) Left outer gill.-Large piece cut out of ventral edge.

(a) Right outer gill.-LLarge piece cut out of ventral edge.

(b) Right inner gill.-Piece cut out of ventral edge.

(c) Left inner gill.-Piece cut out of ventral edge. (a) Piece sloughed off. Cut made at extreme posterior end of gill, very close to dorsal food groove; as all interlamellar junctions removed, the lamellæ separated, and the cut ventral ends of each have rounded off independently, with irregular edges and without formation of food groove.

(b) No sign of injury when gills examined with microscope. Regeneration of epithelium had occurred.

(c) No sign of injury when gills examined with microscope. Regeneration of epithelium had occurred, and in cases where filaments had been cut through, fusion of cut ends had also taken place.

(d) Regeneration of food groove occurred, also some slight regeneration, with apparent fusion, of filaments.

(a) Regeneration of food groove occurred, but no appreciable regeneration of filaments. New food groove was very noticeable as it was almost unpigmented, while that on old part of gill was very darkly pigmented. The gap was somewhat smaller than the piece removed, owing to the inward bending of the filaments at either end.

(b) As for right outer gill.

(c) As for right outer gill. 


\section{REGENERATION.}

Regeneration of the gill of Mytilus consists of the formation of $(a)$ food groove and $(b)$ gill filaments. These may be considered separately, as the former may occur without any appreciable regeneration in length of the gill filaments.

\section{(a) Food Grove.}

A food groove was formed at the cut edge of the gill in all cases, with but one exception, and is apparently always formed, if the cut edges of the filaments of the descending lamella are able to touch and so to fuse with those of the ascending lamella. In the exceptional case (see J, Table I), the cut ends of the descending and ascending filaments had not fused together, but had rounded off independently, the two lamellæ being unconnected in the region of the injury. The ventral edges of the lamellæ were irregular, the filaments having irregularly swollen ends, and no food groove had been formed. There was some fusion of the filaments side by side, towards the ventral edge, and they appeared to be in a somewhat degenerating condition. The cut in this instance was made at the extreme posterior end of the gill where the filaments are either without interlamellar junctions, or there is only one to a filament; such junctions as existed were evidently in the piece of gill which sloughed off following the cut, and there was therefore nothing to prevent the remaining parts of the lamellæ from separating; the non-fusion of their cut ends was apparently due to this cause.

Mussels, which have been found with the ventral edges of the gills in a jagged condition, have been noticed to have continuous, though irregular, ventral food grooves, and offer additional evidence that a groove is practically always formed at the cut edge. An example of regeneration of a food groove following natural injury is sketched in Figure 18, B, of a previous paper on abnormal gills in this journal (2, p. 512).

It was found that two secondary folds bearing food grooves were present on the descending lamella of the left outer gill of the experimental Mussel A, as shown in Figure 2: some slight abnormality of the filaments occurred in corresponding positions on the ascending lamella. It is perhaps probable that the injuries done to the gill are accountable for these, though there appeared to be no difference in pigmentation between the secondary folds and the old part of the gill. It will be seen that the secondary groove near the ventral edge of the gill, runs from the main food groove in an anterior and dorsal direction, so that the current along its food groove diverges from that of the main groove instead of joining it, as is more usual in secondary grooves on gills (see 1). On most of the filaments composing the larger secondary 
groove there was no reversal of beat of the frontal cilia, but on a very few it occurred for a short stretch near the secondary groove. There appeared to be no change in direction of the ciliary current on the filaments composing the smaller, and more dorsal secondary groove, but the filaments. were not examined singly.

Gills (see C, D, E, F and J, Table I) which had been cut with a scalpel obliquely across the filaments-care being taken not to reach the ventral edge of the gill-in some cases the gill being unsupported, and in others. supported by the blade of an oyster opener inserted behind the gill, curiously showed not the slightest sign of injury when examined under the microscope at the end of the experiments. The doubt arose, considering the difficulty of working with mussels with the valves only slightly separated, whether any cut had actually been made. Investigation with an opened mussel showed that if the gill was unsupported the frontal epithelium alone was cut, the chitinous skeleton being sufficiently resistant to prevent cutting of the entire filament. Following the cut, the epithelium peeled off away from it, leaving the chitinous skeleton exposed for a stretch of about $1.0 \mathrm{~mm}$. When the gill was supported by the blade of an oyster opener the result varied. In some instances both lamellæ were cut through ; in others only one lamella, though the epithelium of the opposite one was injured; while in others, though the epithelium of both lamellæ was injured, few if any filaments were actually cut through. In all cases the epithelium peeled off for a short distance on either side of the cut or injury. Thus, beyond the cutting of the frontal epithelium, the extent of the injury inflicted with a scalpel is not exactly determinable. However, in the case of the experimental mussels, it is most probable that at least in some instances the filaments were cut through, and there can be no doubt that then the cut ends fused cleanly; where the epithelium alone was cut or injured with consequent peeling off for a short distance, it had regenerated.

This part of the experiment was done in an unsuccessful attempt to cause the formation of secondary food grooves; possibly a tear rather than a clean cut might be more efficacious, but pulling a bent mounted needle, which had been ground to a cutting surface, across the surface of the gill, as was done previously with several mussels, also produced no result. By the latter method the filaments seem to be pulled apart and injured, but not broken.

\section{(b) Gill Filaments.}

Regeneration of the gill filaments did not invariably occur; in only one (see A, Table I) out of four surviving experimental mussels, was regeneration unmistakable and of some amount (Figs. 1, 2 and 3). In one area on each of the two left gills of this mussel (Figs. 2 and 3) the piece regenerated 
was as great or slightly greater in amount than that lost; the maximum length of filament regenerated, $7 \cdot 3 \mathrm{~mm}$., occurred in a deep narrow area on the left inner gill (Fig. 3), where, however, regeneration was not complete. The rate of regeneration in these gills would appear to have been rather greater than on the right inner gill of the same mussel (Fig. 1), where the greatest length of filament removed was about $5 \cdot 4 \mathrm{~mm}$., while the greatest length regenerated was about $3 \cdot 2 \mathrm{~mm}$.; it may be that the shape of the piece severed from the gill has some bearing on this, a narrow deep gap being more rapidly filled in than a broad shallow one.

In two mussels (B and J, Table I) some slight amount of regeneration appeared to have taken place, but it was difficult to distinguish, as owing to the very pale tint of the gills there was no appreciable difference in

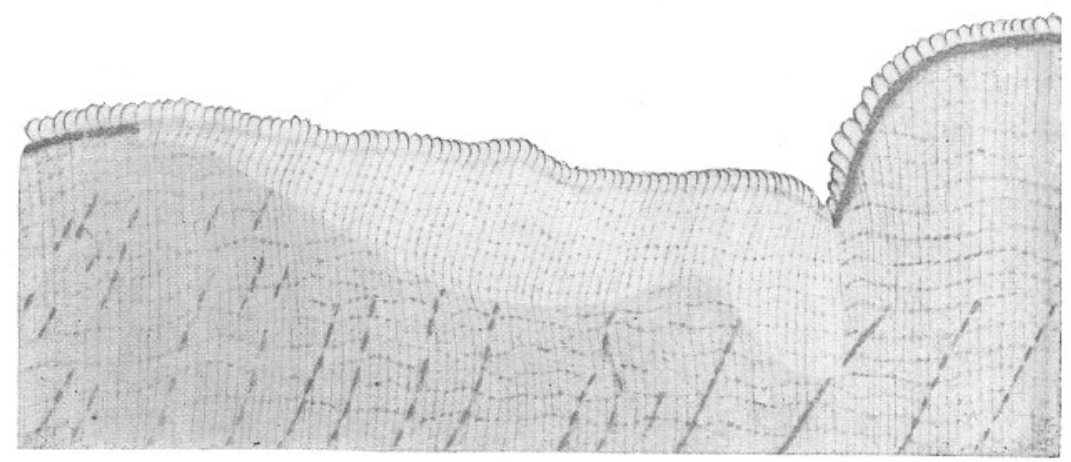

Fig. 1.-Mussel A. Regenerated area on right inner gill; ascending lamella sketched. An attempt has keen made to indicate the difference in degree of pigmentation of the old and new parts. The dark line underlying the food groove in the original part of the gill, represents the line of orange or brown pigment normally found in this position ; the dark oblique lines represent interlamellar junctions ; the dotted wavy horizontal lines, ciliated dises. It will be noticed that a few filaments bordering on the injured area anteriorly, that is at the deepest part of the cut, appear either to have not shared in the growth of the gill, or become reduced in length. (Anterior is on the right.) $\times$ ca. $6 \frac{1}{4}$.

degree of pigmentation of the old and new regions. It was judged to have occurred partly on a comparison of the size of the pieces removed with the size of the gaps left in the gills at the end of the experiment, and partly on a consideration of the form of the filaments.

At the junction of the old and new part of the gill there is generally a slight bend in the filaments (Fig. 4). In some cases (see Fig. 5) there may be lateral fusion of the cut ends of some of the filaments so that two or three will grow forward as one, and as a result there are fewer in the new part than in the old. The ventral continuation of fused filaments is shown by sections to be single in structure as well as in appearance (Fig. 6, p. 562), as might be expected if this part were due to new growth; if it were due to fusion side by side of existing filaments this would in all probability be 


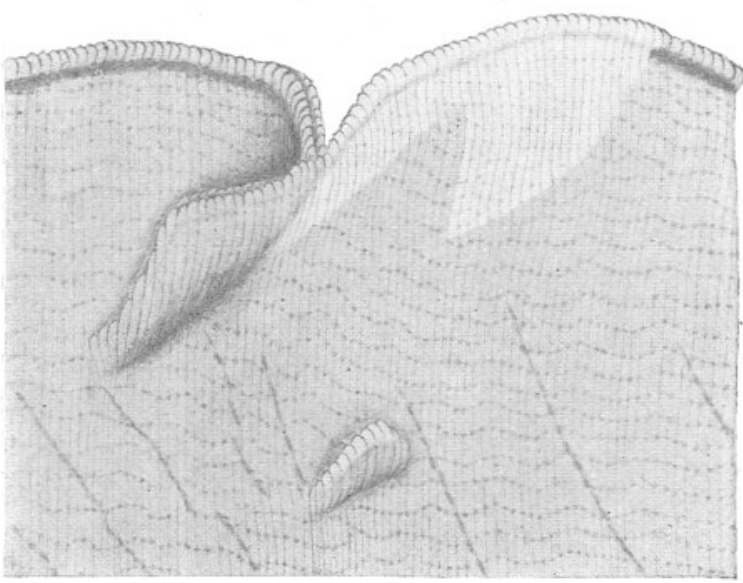

FIG. 2.-Mussel A. Regenerated areas on left outer gill ; descending lamella sketched. Two secondary folds with food grooves are shown. (Anterior is on the left.) $\times$ ca. $6 \frac{1}{4}$.

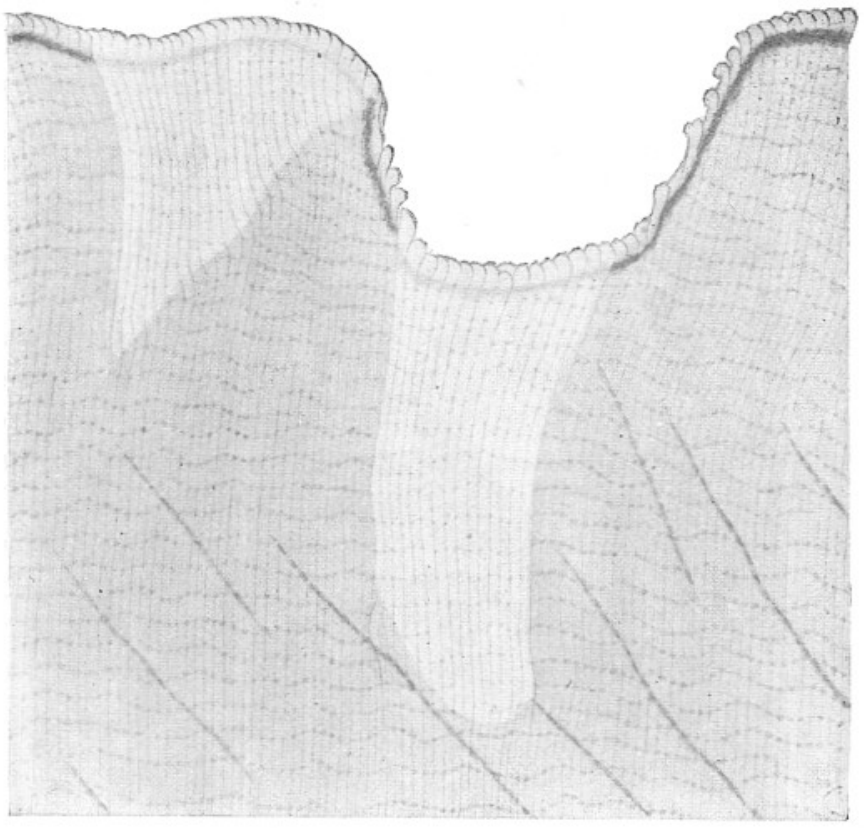

Frg. 3.-Mussel A. Regenerated areas on left inner gill ; ascending lamella sketched. (Anterior is on the left.) $\times$ ca. $6 \frac{1}{4}$. 
apparent in duplication of the chitinous supports in the fused part (see $\mathbf{2}$,

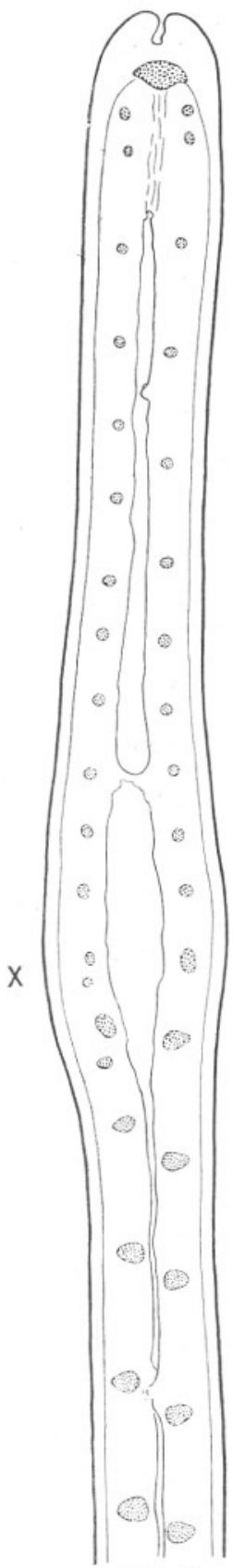

Fig. 4.

p. 507). This lateral fusion of the eut ends of certain of the filaments, with forward growth as a single filament, resulted in an irregular number in the descending and ascending lamellæ, and as a consequence, along the ventral edge of the gill instances occurred of the fusion of the ventral ends of two filaments in one lamella, with the ventral end of one in the opposite lamella.

But the ease with which slight regeneration can be detected depends largely on the depth of pigmentation of the original part of the gill. The characteristic appearance of the normal gill-when looked at as a whole-with $(a)$ the line of orange or brown pigment beneath the main ventral food groove; $(b)$ the more opaque, sometimes darker, wavy lines running longitudinally across the surface of the lamella, due to the presence of ciliated discs; and $(c)$ the more opaque, and sometimes darker, oblique lines, due to the presence of interlamellar junctions, is shown in the old part of the gill in the sketches in Figures 1,2 and 3. These three sets of markings on the gill are more clearly visible in some gills than in others, depending largely on the variation in general depth of pigmentation of the gills, which occurs in different individuals. In two mussels (B and $\mathrm{J}$, in Table I) the gills were so pale in tint that even the regenerated food groove showed up very faintly, though under the microscope the difference in pigmentation could be fairly easily seen. In one mussel (A, in Table $\mathrm{I})$, in which an appreciable amount of regeneration had occurred, the regenerated areas were obvious at a glance owing to the difference in intensity of pigmentation between them and the old part of the gill (Figs. 1, 2 and 3). The newly formed parts were practically unpigmented, and the dark line of pigment normally present

Ftg. 4.- Side view of filament from a region of regeneration. The junction (at $x$ ) between the old and new parts of the filament is marked by a slight bend: the difference in the size of the ciliated discs in the two regions is noticeable, those in the new part being considerably smaller than those in the old part. One interlamellar junction is present in the new region and also the beginning of a second. Bouin's fixative. $\times$ ca. $35 \frac{1}{2}$. 
running parallel with the free ventral edge of the gill was lacking; the pigment granules seen under the microscope in this position being too few to give any appearance of colour. In the case of the right-inner gill of mussel A (Fig. 1) the oblique dark lines on the old part of the gill, due to the presence of interlamellar junctions, were seen to stop abruptly when reaching the regenerated portion. Under low powers of the microscope, or with a lens, the dark wavy lines caused by the presence of the ciliated discs on the filaments were also seen apparently to stop, or alter in character, against the new tissue in all cases of regeneration of the gills of this mussel (Figs. 1,2 and 3): in the regenerated region

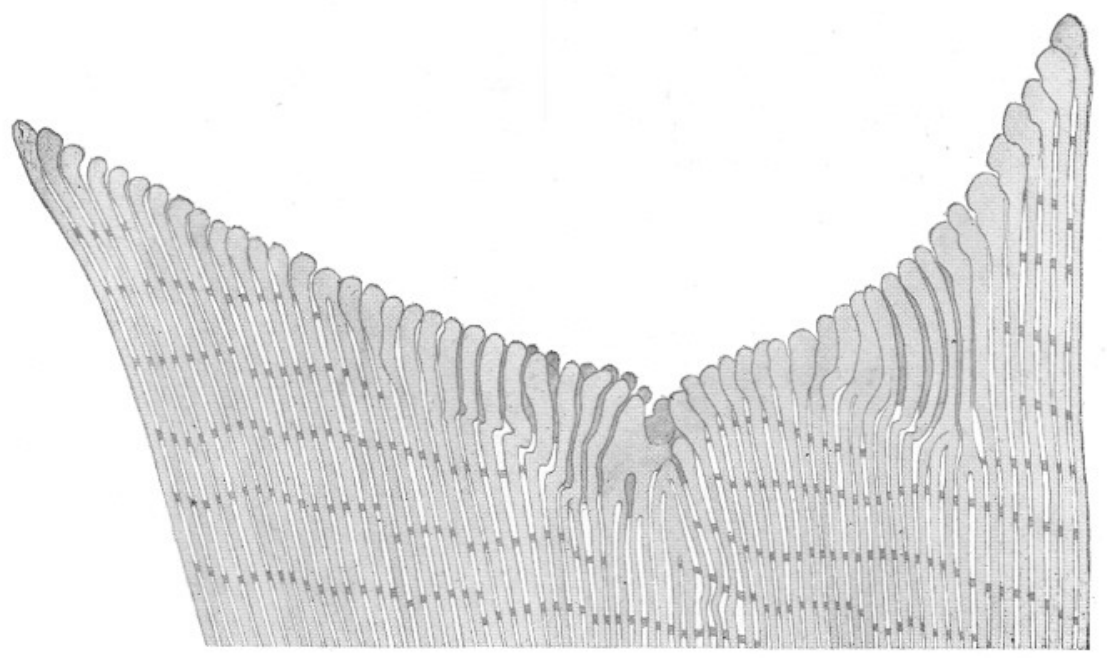

Fig. 5.-Mussel B. Left outer gill, ascending lamella. A small region at the depth of the gap has been sketched, to show the tiny irregular area of regeneration, and the apparent fusion of some of the filaments. In this instance there was no appreciable difference in colour between the old and new parts. (Anterior is on the right.) $\times$ ca. $18 \frac{1}{4}$.

these lines, though present, were faint, and difficult to follow. The cause of the difference in intensity of the lines was apparent on examining single gill filaments in side view; in the regenerated part of the gill filament the ciliated discs were on an average about half the size of those in the original part of the filament (see Fig. 4), and were practically destitute of pigment granules. In those instances examined, they also differed in shape, being more or less circular, while those in the old part were somewhat triangular. Single filaments stripped from one part of a gill (preserved in formalin) where regeneration had occurred, showed the mucus cells, which were plentiful on the abfrontal face in the old part, to be absent, or not visible in a total unstained preparation, in the new part. This, however, is probably a point of little importance as the condition of the mucus glands is 
likely to vary in different parts of an uninjured filament, and at different times. Microscopic transverse sections through the old and regenerated parts of the gill showed no appreciable difference in the development of the chitinous supports. The difference in pigmentation between the old and
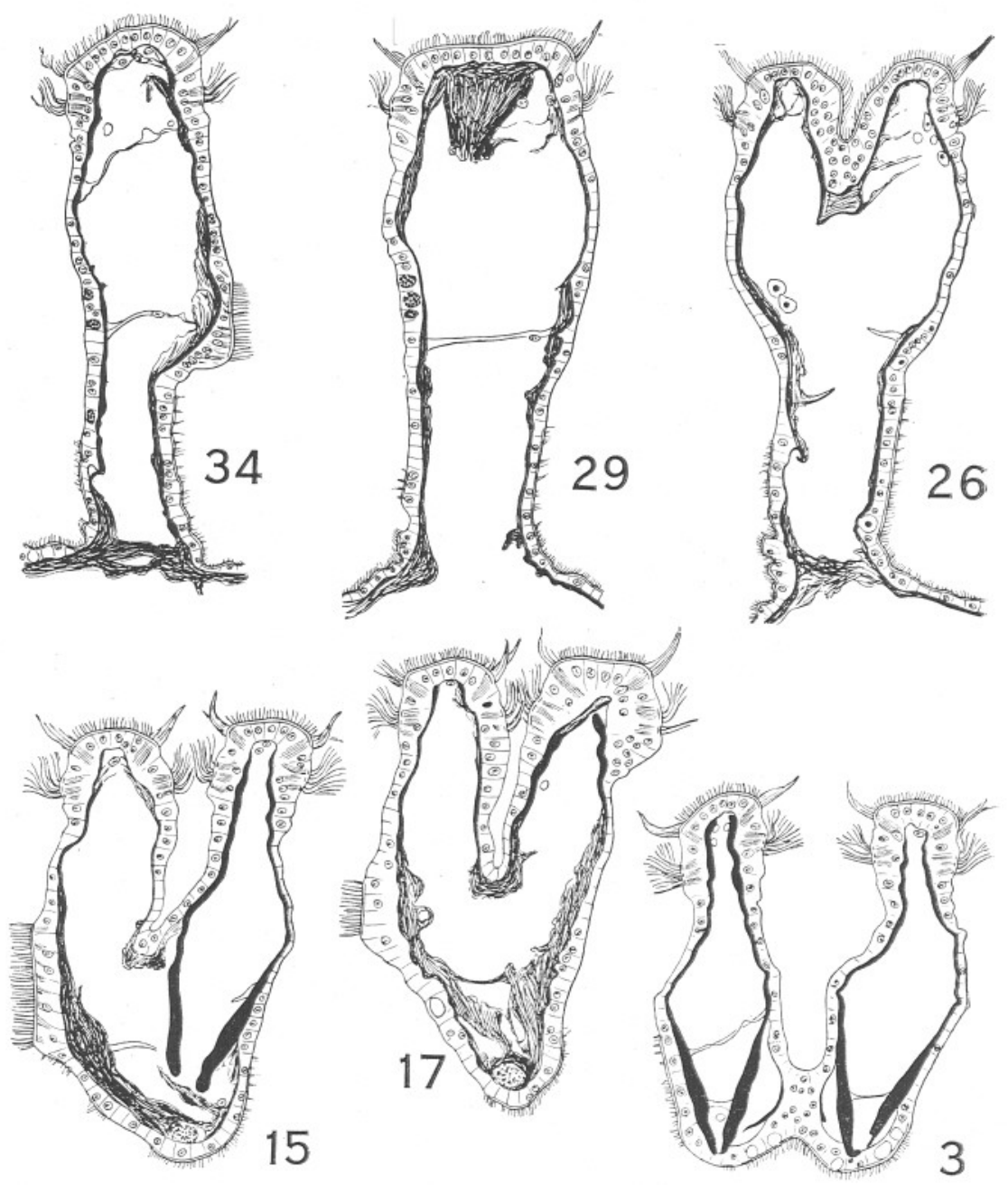

Fig. 6.-Mussel B. Left outer gill, ascending lamella. Transverse sections from a series passing through the junction of the two fused filaments on the extreme right of Fig. 5, to show the change undergone by the chitinous supports and the simple character of the ventral continuation of the filaments. Some slight fusion of the two filaments was evident in the two sections preceding the most dorsal one sketched, namely, 3 . The sections are numbered according to their position in the series, so that the number of intervening sections may be known. In the 22 nd and following sections (see 26, 29, 34 ) the filament was connected with several, more posterior, filaments and also with a group in the opposite lamella. The pale staining chitin is indicated by shading. Bouin's fixative; Mallory's Triple Stain. Sections ca. $8 \mu$ thick. $\times 270$. 
new food grooves was clearly visible in sections passing from one to the other : these were cut a day or two after fixation and the pigment granules had retained much of their original yellow colour.

Interlamellar junctions, to the number of two, have been observed in the regenerated part of some of the few filaments examined singly : they were finer than those in the original part of the filament. In the new part, some at least of the interlamellar junctions appear to be formed by outgrowth from the abfrontal face of one filament (Fig. 7), three cases being noticed of small outgrowths in this position; two of these, of which note was especially taken, were from the ascending filament and were respectively about 1.2 and $2.59 \mathrm{~mm}$. from the ventral edge of the gill. This is
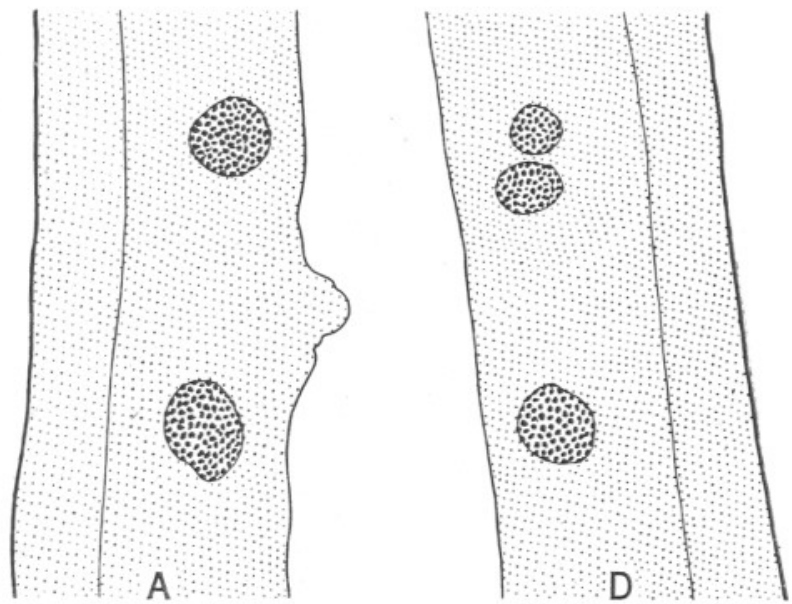

FIG. 7.-Sketch showing origin of interlamellar junction on abfrontal face of ascending part of regenerated filament. The small outgrowth was about $2.59 \mathrm{~mm}$. from the ventral edge of the gill. Bouin's fixative. $\mathrm{D}$ and $\mathrm{A}$, descending and ascending filaments respectively. $\times 140$.

of interest in relation to the method of formation of these junctions in the normal development of the gill. According to Rice, they arise through the perforation of a short interlamellar septum, present between the ventral ends of the descending and ascending filaments (see 12, Fig. 8, p. 73), and such as is found much more fully developed in Modiolus. This he refers to as the Modiolus stage in the development of the filaments of Mytilus.

In the regenerated areas, as shown by sections through the regenerated part of the left outer gill of Mussel B (Fig. 5), much interfilamentar as well as interlamellar connection may occur, in part obliterating the interlamellar space. The condition of the filaments shown in Figure 8 was seen in part of the regenerated area, the particular section sketched being 
across some of the normal-looking filaments to the right of the median area of fusion, and between the two most ventral rows of ciliated discs seen in Figure 5. In some parts a similar condition of groups of filaments existed through much of their regenerated length (ca $1.0 \mathrm{~mm}$.).

In a certain number of mussels slanting cuts were made, with scissors, from the ventral edge of the gill in a dorsal and anterior direction, in this way separating a triangular piece from organic connection with the gill, but without removing the piece, which remained connected merely by the

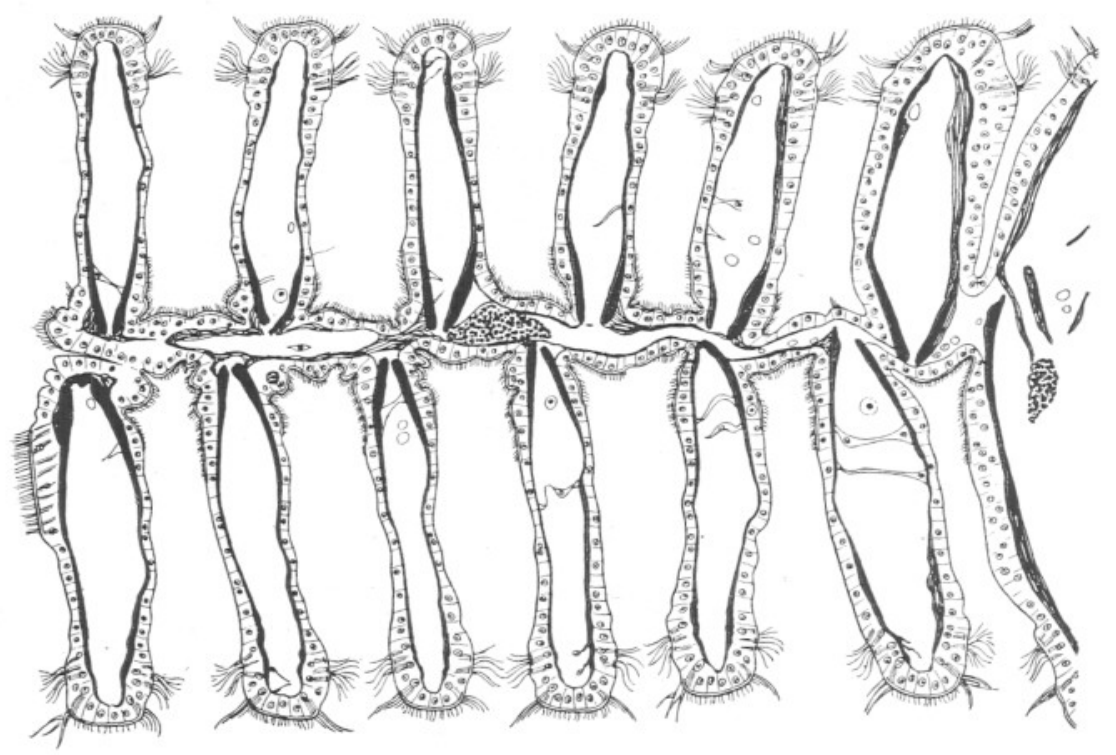

FIG. 8.-Mussel B, left outer gill. Transverse section through part of new area sketched in Fig. 5, showing the filaments in the two lamellæ connected by a median band of tissue. A mass of pigment is present at one place within this median connection. This section is across some of the normal-looking filaments to the right of the median area of fusion, and between the two most ventral rows of ciliated discs, seen in the sketch. Bouin's fixative; Mallory's Triple Stain. Sections ca. $8 \mu$ thick. $\times 200$.

ciliated dises on the most anterior and longest length of filament. In the four gills treated in this way (mussels B and $J$ with one gill in each, and mussel A with two gills cut), the pieces had more or less completely degenerated and fallen off. In one instance (left inner gill of B), it appeared that the cut ends of some few disconnected filaments at the depth of the cut (the longest pieces separated) had joined up again, but somewhat irregularly, the ventral ends of two joining the dorsal end of one and vice versa : in this case also, while most of the cut ends of filaments had sloughed off, there were five or so short lengths of filaments separated dorsally from the main part of the gill by a tiny space, but attached anteriorly 
and posteriorly; but it is most probable that these filaments were in connexion with each other and the rest of the gill by some organic junctions.

In a previous experiment in June, 1929 (see 1, p. 961), some organically separated ends of filaments were still connected, after 112 days, with each other and with the main part of the gill merely by their ciliated discs. It, therefore, appears that though such cut pieces of filament may persist for a certain time, after a longer period they are very liable to slough off.

In one mussel (A, in Table I) the two left gills were cut in the manner described above, and regeneration occurred, new tissue partly or entirely filling up the triangular gaps (see Figs. 2, 3).

It may be noted that even after preservation in formalin, or in Bouin's picro-formol for rather more than three months, regenerated areas were recognisable owing to their greater translucence.

\section{DISCUSSION AND SUMMARY.}

Experiments have shown that the gill of Mytilus is capable of regeneration, and that this may occur in less than eight months. It may be confined to the formation of a food grove at the cut edge of the gill, without appreciable regeneration in length of the gill filaments. Regeneration of a food groove appears always to occur at the cut edge, if the ends of the descending and ascending filaments are able to touch and so to fuse. On the other hand, regeneration of gill filaments does not seem to occur invariably, and when it does the rate is slow, at least under experimental conditions and in mussels of a length of about $7 \cdot 0$ to $8 \cdot 0 \mathrm{~cm}$., such as were used for the experiments : it is possible that regeneration would occur more surely and rapidly in young mussels, but owing to the thinness of the shell they would be more difficult to wedge open without fracturing. Coulthard (6, p. 136), however, says that "The rate of growth is independent of size in the mussel, being apparently influenced only by the environment." Perhaps the lack of an abundant food supply under the conditions of the experiments should be taken into consideration, though it is well known that in general the amount of food available to an animal has little influence on regeneration $(\mathbf{9}$, p. 27$)$. The salinity of the water in general circulation is about $36-37^{\circ}$ oo, that is, higher than normal sea-water, which is about $35^{\circ} \%$, and would be considerably higher than the optimum salinity for growth (see Flattely and Walton, 7, p. 81). This may also possibly have a retarding effect on the initiation of regeneration and the rate.

It is obscure why regeneration does not always occur ; so far as could be judged there was no difference in the method of making the cuts, there was little difference in the size and therefore the age of the mussels used, 
the cuts were made in approximately the same position on the gill (somewhere between the posterior and middle third of the gill, this position being chosen simply because it was the easiest to reach), and at the end of the experiments - none of which was terminated before the end of eight months-there was little difference in the condition of the various mussels.

\section{LITERATURE.}

1. Atrins, D. On Abnormal Conditions of the Gills in Mytilus edulis. Part I. Journ. Mar. Biol. Assoc. Vol. XVI (N.S.), pp. 919-970, 1930.

2. Atkins, D. Part II. Ibid. Vol. XVII (N.S.), pp. 489-543, 1931.

3. Bloomer, H. H. On some malformed specimens of Anodonta cygnea L. Journ. Malacol., London, Vol. VII, pp. 136-138, 1900.

4. Bloomer, H. H. Notes on some further malformed specimens of Anodonta cygnea L. Ibid. Vol. VII, pp. 177-178, 1900.

5. Bloomer, H. H. Notes on some further malformed specimens of Anodonta cygnea L. Ibid. Vol. IX, p. 96, 1902.

6. Coulthard, H. S. Growth of the Sea Mussel. Contr. Canad. Biol. and Fish. Vol. IV (N.S.), No. 10, pp. 121-136, 1929.

7. Flattely, F. W., and Walton, C. L. The Biology of the Seashore. Sidgwick and Jackson. London. 1922.

8. Korschelt, E. Regeneration and Transplantation. Berlin. 1927.

9. Morgan, T. H. Regeneration. Macmillan \& Co. New York and London. 1901.

10. Pelseneer, P. Les variations et leur hérédité chez les Mollusques. Acad. Roy. Belgique. Mémoires, 2nd sér. Tome V. 1920.

11. Poyarkoff, E. Incubation des Embryons et régénération des branchies chez les Cyclas (Sphohrium corneum, L.), (Note préliminaire). Arch. Zoo. Exp. et Gén. 5 sér., Tome V, pp. exxvexxxviii, 1910.

12. Rice, E. L. Gill development in Mytilus. Biol. Bull., Woods Hole, Vol. XIV, pp. 61-77, 1908. 